\title{
Fundic Gland Polyps in Atypical View
}

\author{
Mesut AYDIN ${ }^{1}$, Elif Tuğba TUNCEL ${ }^{2}$, Erhan ERGİN² \\ ${ }^{1}$ Van Yüzüncü Yıl University Faculty of Medicine, Van, Turkey \\ ${ }^{2}$ Manisa City Hospital, Manisa, Turkey
}

\begin{abstract}
Stomach polyps are pedunculated or sessile lesions that arise from the gastric epithelium or submucosa and project into the lumen. Most of them are detected incidentally during an endoscopy performed for another reason. Here we aimed to present an atypical case of the gastric polyp.
\end{abstract}

Turk J Int Med 2021;3(Supplement 1):S52-S54 DOI: $\underline{10.46310 / \text { tjim. } 874433}$

Keywords: Fundus gland polyps, endoscopy, patolgy

\section{Introduction}

Gastric polyps are divided into three groups as epithelial polyps, hamartomatous polyps, and mesenchymal polyps. Epithelial polyps are the most common type. Fundic gland polyps and hyperplastic polyps are the most common epithelial polyps. Adenomatous polyps, NETs (carcinoids), ectopic pancreas, pyloric gland adenomas are less common epithelial polyps. Hamartamatous polyps, Peutz-Jeghers, juvenile polyps are polyps known as Cowden syndrome. On the other hand, mesenchymal polyps are rarely seen as inflammatory fibroid polyp, gastrointestinal stromal tumor, and leiomyoma. Fundic gland polyps (FGP) is the most common type of gastric polyp, with a rate of $47 \%$.
Its frequency has increased due to the widespread use of proton pump inhibitors, especially in western societies. FGPs are mostly multiple polyps smaller than $1 \mathrm{~cm}$ and are seen in the fundus and proximal corpus. They are flat, sessile, transparent, and round lesions. ${ }^{1}$ The rate of malignancy is low. Its association with atrophic gastritis and $\mathrm{H}$. pylori is rare. Histologically, dilatation in the auxintic glands and hyperplasia in the enterochromaffin cells are observed. There are three subtypes: sporadic type; one or several pieces are seen. It is common in people negative for $\mathrm{H}$. pylori. The type associated with proton pump inhibitors (PPI) is seen frequently (about 4 times more) and in large numbers. Polyps regress after discontinuation of

\footnotetext{
Received:February 03,2021;Accepted:March 3,2021;Published Online:March 6, 2021
Address for Correspondence:
$\begin{aligned} & \text { ElifTugba TUNCEL } \\ & \text { Manisa City Hospital, Manisa, Turkey } \\ & \text { E-mail:ettuncel@gmail.com }\end{aligned}$
Jurkish
Meurnal of
Medicine
}



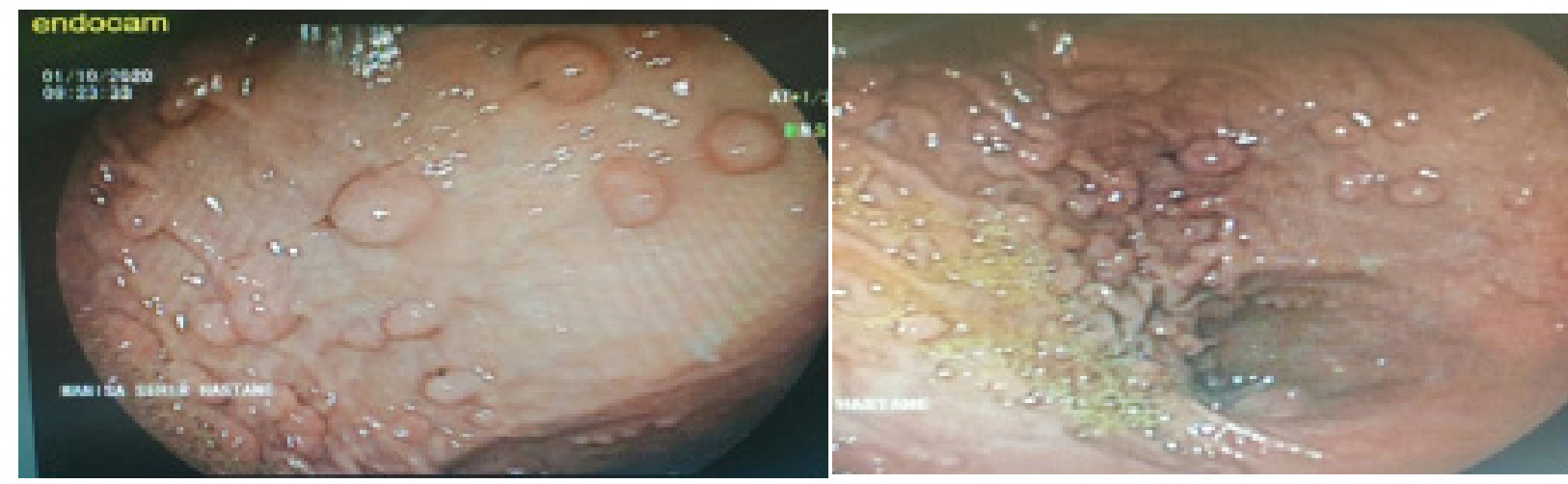

Figure 1. Endoscopic view of polyps.

the drug. The type has been seen together with FAP (familial polyposis). Familial polyposis syndrome should be questioned in the presence of sporadic FGP. APC gene mutation is an important cause in pathogenesis. It is not associated with $\mathrm{H}$. pylori and atrophic gastritis. FGP is seen in $95 \%$ of patients with FAP. There is a risk of developing dysplasia in $25-40 \%$ of the FGPs seen in these patients. ${ }^{2,3}$

\section{Case Report}

The male patient, 69 years old, presented with nausea, swelling, and intermittent epigastric pain for about 6 months. The patient's medical and family history was unremarkable, except for the use of intermittent PPIs. Physical examination revealed blood pressure $120 / 70 \mathrm{mmHg}$, pulse 72 beats/ min, and fever of $36.8{ }^{\circ} \mathrm{C}$. There was no pathological finding in the systemic examination. In the laboratory findings, leukocyte $5,600 \mathrm{~K} / \mathrm{UI}$, hemoglobin $13 \mathrm{~g} / \mathrm{dL}$, ESR $10 \mathrm{~mm} / \mathrm{h}$, creatinine $0.6 \mathrm{mg} / \mathrm{dL}$, total/direct bilirubin $1.1 / 0.6 \mathrm{mg} / \mathrm{dL}$, AST/ALT 15/10 U/L, LDH 143 U/L, GGT 11 U/L, HBsAg (-), anti-HCV (-), anti-HBs (+), iron $117 \mu \mathrm{g} / \mathrm{dL}$, ferritin $152 \mathrm{ng} / \mathrm{mL}, \mathrm{B} 12$ vitamin 261, folic acid $3.5 \mathrm{ng} / \mathrm{mL}$, and TSH $0.8 \mathrm{IU} / \mathrm{mL}$. Tumor markers were within normal limits. There were multiple and different polyps in upper gastrointestinal endoscopy, with the largest $1 \mathrm{~cm}$ in the fundus and corpus. Polypectomy was performed on random large ones (Figure 1). Colonoscopy was normal. Whole abdominal tomography detected simple cysts of 2 and $4 \mathrm{~cm}$ in size in segments 6 and 8 of the liver. Other structures were usual. FGPs were pathologically diagnosed.

\section{Discussion}

FGPs are the most common stomach polyps. With the widespread use of PPIs, their incidence has increased. It is considered to regress after the cessation of PPIs. Its association with chronic gastritis or $\mathrm{H}$. pylori gastritis is rare. ${ }^{3}$ The risk of malignancy is low. During endoscopy, it is often not possible to directly distinguish between malignant and benign gastric polyps. Sometimes, endoscopic appearance and pathological diagnosis may not be compatible. ${ }^{3,4}$ Therefore, pathological evaluation after polypectomy is diagnostic. In our rare and interesting case, diffuse gastric involvement and multiple polyps of different shapes and sizes suggested malignancy, but FGPs were pathologically diagnosed.

\section{Conflict of Interests}

Authors declare that there are none.

\section{Acknowledgment}

This study has been presented in $17^{\text {th }}$ Uludag Internal Medicine National Winter Congress, $6^{\text {th }}$ Bursa Family Medicine Association National Congress, $11^{\text {th }}$ Uludag Internal Medicine Nursing Congress, 5-7 March 2021, Bursa, Turkey. 


\section{References}

1. Goddard AF, Badreldin R, Pritchard DM, Walker MM, Warren B; British Society of Gastroenterology. The management of gastric polyps. Gut. 2010 Sep;59(9):1270-6. doi: 10.1136/gut.2009.182089.

2. Martin FC, Chenevix-Trench G, Yeomans ND. Systematic review with meta-analysis: fundic gland polyps and proton pump inhibitors. Aliment Pharmacol Ther. 2016 Nov;44(9):915-25. doi: 10.1111/apt.13800.

3. Gencosmanoglu R, Sen-Oran E, Kurtkaya-Yapicier O, Avsar E, Sav A, Tozun N. Gastric polypoid lesions: analysis of 150 endoscopic polypectomy specimens from 91 patients. World J Gastroenterol. 2003 Oct;9(10):2236-9. doi: 10.3748/wjg.v9.i10.2236.

4. Carmack SW, Genta RM, Schuler CM, Saboorian MH. The current spectrum of gastric polyps: a 1-year national study of over 120,000 patients. Am J Gastroenterol. 2009 Jun;104(6):1524-32. doi: 10.1038/ajg.2009.139. 